\title{
A Prospective Study of Headache after Carotid Endarterectomy: Incidence and Clinical Characteristics
}

\author{
Lucas Alverne Freitas de Albuquerque ${ }^{1 *}$, Marcos Dellaretti ${ }^{1,2}$, Gervásio Teles Cardoso de Carvalho ${ }^{1,2}$, \\ Wilson Faglioni Júnior ${ }^{1,2}$, Atos Alves de Sousa ${ }^{1,2}$ \\ ${ }^{1}$ Department of Neurosurgery of Santa Casa de Belo Horizonte, Belo Horizonte, Brazil; ${ }^{2}$ Faculdade de Ciências Medicas de Minais Gerais, \\ Belo Horizonte, Brazil. \\ Email: \{'lucasalverne, faglioniwj\}@yahoo.com.br, mdellaretti@mac.com, \{gervasiocarvalho, atossousa\}@gmail.com
}

Received December $8^{\text {th }}, 2011$; revised January $18^{\text {th }}, 2012$; accepted February $24^{\text {th }}, 2012$

\begin{abstract}
Headache associated with Carotid Endarterectomy (CEA) is a known condition; however, its incidence and etiology are not well defined. In this study, we determined the incidence and evaluated the characteristics of headache following CEA. This prospective study was conducted between January and July 2009, in 32 patients submitted to CEA. 68.7\% of patients were male; mean age was 67.3 years-old. Headache incidence was $37.5 \%$, ipsilateral to the CEA in $91 \%$ of patients; pressure was the most common pain quality (81.2\%) and affected the frontal region alone in $37.5 \%$ of headache episodes. All headache episodes were of mild intensity. No correlation ( $p>0.05)$ was found between sexes and no significant value $(p>0.05)$ was determined between the presence of headache and the mean degree of stenosis in the ipsilateral and contralateral carotid operated. Headache following CEA is a common condition; in most cases it is ipsilateral to the procedure, pressure type, mild and self-limiting.
\end{abstract}

Keywords: Headache; Carotid Endarterectomy; Stroke; Complication

\section{Introduction}

Carotid endarterectomy (CEA) for carotid stenosis was first successfully performed in 1954 by Eastcott et al. [1]. The operation has since been performed widely and nowadays it is based on the NASCET or ECST criteria [2,3]. The benefits of the procedure depend on the degree of stenosis. Important complications of CEA can occur, including postoperative dissection of the intimal flap, infarction due to distal thrombosis, embolism and hypotension [4]. Headache associated with CEA is a known complication described in the International Classification of Headache Disorders 2nd Edition [5]. Usually the headache is mild and presents no important clinical repercussions, but it can be a very disturbing symptom [5].

The incidence of headache associated with CEA is not as well defined as the etiology of this symptom. Some studies reported the incidences of as low as $24.5 \%$ and others reported incidences of as high as 62\% [6,7].

The objectives of this study were to determine the incidence and evaluate the characteristics of headache following CEA.

\footnotetext{
"Corresponding author.
}

\section{Patients and Methods}

\subsection{Study Design}

Between January and July 2009, a total of 32 patients were submitted to CEA procedures at the Department of Neurosurgery, Santa Casa Hospital. This prospective study comprises the evaluation of headache at four moments: 1) immediately following the procedure; 2) after 24 hours; 3) after 48 hours; and 4) after 10 days.

The variables analyzed were sex, age and headache characteristics: laterality, site, severity, quality, frequency, duration, associated symptoms, time of onset, trigger.

\subsection{Surgical Technique}

Regional anesthesia with mild sedation was used in all CEA procedures $[8,9]$. With the patient in the supine position, the head is turned $30^{\circ}$ away from the side of the operation and the neck is slightly extended. The incision is outlined along the anterior border of the sternocleidomastoid muscle, with an anterior curve in the inferior border and a superior curve in the direction of the tip of the mastoid process.

After the skin and subcutaneous incision has been com- 
pleted, dissection is performed through the platysma and along the anterior border of the sternocleidomastoid muscle. The common carotid artery is exposed in the lower part of the incision and followed superiorly, thus identifying the bifurcation and exposing the proximal 3 to 4 $\mathrm{cm}$ of the internal carotid artery (ICA). The origin of the external carotid and superior thyroid arteries are then isolated.

Manipulation during the dissection of the carotid bifurcation and proximal ICA are kept to a minimum so as to avoid dislodgement of embolic material from the atherosclerotic plaque. Prior to the cross-clamping of the carotid artery, heparin $(1 \mathrm{U} / \mathrm{kg})$ is administered intravenously as a bolus to all patients. After heparinization, a test of tolerance of flow interruption is performed by clipping the ICA for $2 \mathrm{~min}$. When the patient develops a neurological deficit during this test, the clip is removed and the deficit is usually reversed in minutes. These patients require a shunt during the CEA. Before the cross-clamping to install the shunt, mannitol $(1 \mathrm{~g} / \mathrm{kg})$ is administered intravenously and the anesthesiologist is asked to induce mild hypertension (20 to $30 \mathrm{mmHg}$ ) to protect the brain. This usually permits installation of the shunt before the patient develops symptoms of brain ischemia again. When occlusion of the ICA is tolerated for 2 min with no neurological deficit, the shunt is not necessary.

The microscopy arteriotomy is initiated in the common carotid artery and extends upward to the ICA beyond the end of the atherosclerotic plaque. Dissection of the plaque is performed using a Penfield dissector, initiating in the common carotid artery and distally to the ICA. Finally, the plaque is removed from the external carotid artery. The artery is closed using 6.0 monofilament sutures initiating at both ends of the arteriotomy. Before final closure, back bleeding from all the vessels is performed in order to eliminate air and debris from the lumen.

After completing the arteriotomy closure, deocclusion of the arteries is achieved in a manner that expels any air or debris to the external carotid artery so as to reduce the risk of embolic stroke. A: The clip on the superior thyroid artery is removed just before the final sutures to maintain the lumen full of blood and expel air bubbles. B: The external carotid artery is opened. C: The common carotid artery is opened permitting blood and debris to flow out to the external carotid artery. D: The common carotid artery is again occluded and the internal carotid artery opened allowing any debris to be washed back to the external carotid artery. E: The internal carotid artery is clipped again and the common carotid artery is opened. About a minute later, the internal carotid artery is reopened.

Finally, the surgical field is carefully inspected for hemostasis and then the wound is closed in two layers using interrupted sutures. Heparin is not reversed at the end of the procedure.

\subsection{Statistical Analysis}

All data are expressed as mean \pm standard deviation (SD). The Fisher Test was used for statistical analysis, with $\mathrm{p}<$ 0.05 considered statistically significant; all analyses were performed using the statistical software package, SPSS version 16.0 (SPSS Inc., Chicago, IL).

\section{Results}

\subsection{Patient Characteristics}

Of the 32 patients interviewed, 22 were male (68.7\%); the mean age was 67.3 years-old (range: 35 to 89 years-old). The side of surgery was equally distributed, with $50 \%$ performed on the right side and $50 \%$ on the left side.

\subsection{Headache Characteristics (Table 1)}

Headache was a complaint for 12 patients (37.5\%) in this study. Headache was present in: seven (21.8\%) patients immediate following surgery; three (9.3\%) patients 24 hours postsurgery; one (3.1\%) patients 48 hours postsurgery; and in five (15.6\%) patients five days postsurgery, for a total of 16 episodes of headache. The majority of episodes occurred in the first two days following the procedure (68.7\%).

There was no difference in headache incidence according to sex ( $>$ > 0.05), 6/22 (27.2\%) men and 6/10 (60\%) women.

\subsection{Site and Laterality}

The headache was ipsilateral to the CEA in 11 (91\%) patients and in 15 (93.7\%) headache episodes and bilateral in one (6.2\%) episode.

Headache episodes affecting the frontal region alone showed the greatest frequency $(37.5 \%, n=6 / 16)$, followed by the temporal region alone $(25 \%, n=4 / 16)$ and the occipital region alone $(6.2 \%, n=1 / 16)$. Other site combinations were present in five episodes (31.2\%).

\subsection{Severity}

All the 16 headache episodes were of mild intensity. Analgesics were necessary in seven (43.7\%) episodes.

Table 1. Headache characteristics.

\begin{tabular}{ccc}
\hline Incidence & 37.5\% & \\
\hline Site & Ipsilateral 91\% & Bilateral 9\% \\
Main localization & Frontal alone 37.5\% & Temporal alone 25\% \\
Severity & Mild 100\% & \\
Quality & Pressure 81.2\% & Pulsatile 18.7\% \\
Duration & Mean time 259 min & \\
\hline
\end{tabular}




\subsection{Quality}

Pressure was the most common pain quality $(81.2 \%, \mathrm{n}=$ 13/16) followed by pulsatile $(18.7 \%, n=3)$. There were no reports of dull, throbbing, sharp or burning qualities.

\subsection{Duration and Frequency}

The mean duration of pain attacks was 259 min (varying from $1 \mathrm{~min}$ to $24 \mathrm{~h}$ ). The pain lasted for more than one hour in 10/16 (62.5\%) of the episodes.

\subsection{Headache $\times$ Stenosis}

No statistical significant value between the presence of headache and mean degree of stenosis was determined in the ipsilateral $(p=0.43)$ and contralateral $(p=0.36)$ carotid operated (Table 2).

\section{Discussion}

The mechanism of post CEA headache remains uncertain. The three most discussed theories are:

1) Mechanical stretching of the artery $[4,10]$. Preoperative narrowing of the carotid artery followed by sudden disobliteration could lead to a sudden distending force of the full arterial pressure on vessels previously protected by the stenosis.

2) A disorder in the autoregulation of cerebral blood flow. Leviton et al. [10,11] suggested that a reduction of perfusion pressure by the stenosed segment may be associated with regional vasodilation. The development of normal pressure following CEA could lead to a distending force in a vascular bed dilated by such autoregulatory phenomena, resulting in reactive "luxury perfusion";

3) Sympathetic system lesion. Pearce et al. [4] and Marinis et al. [12] believe that regulation of the regional cerebral blood flow is altered by manipulation of the carotid sinus at the bifurcation or by damage to the sympathetic chain in the carotid sheath. These factors could lead to a temporary vascular disturbance that would produce a vascular headache. This would subside spontaneously in a manner similar to that observed in the changes in the vasculature following sympathectomy.

According to The International Classification of Head- ache Disorders $2^{\text {nd }}$ Edition [5], the most frequent headache post CEA (up to $60 \%$ of cases) is a benign selflimiting condition, characterized by a diffuse, mild isolated headache occurring in the first few days postsurgery. The second type (reported in up to $38 \%$ of cases) is a unilateral cluster-like pain with attacks, lasting 2 - 3 hours, occurring once or twice a day. It resolves in about two weeks. The third type is part of the rare hyperperfusion syndrome with a unilateral pulsating and severe pain occurring after an interval of three days postsurgery. It often precedes a rise in blood pressure and the onset of seizures or neurological disorders around day seven.

Table 3 compares the data of this article with the literature data. In the present analyses the incidence of post CEA headache was $37.5 \%$, while the incidence in other reported series varied from $24.5 \%$ to $62 \%$ [6,7,12]. We observed that the headache occurred in first few days following the procedure, as reported by Tehindrazanarivelo et al. [6], in which the episodes totalized $87 \%$ until day five. Sternic et al. [7] affirmed that the pain had a mean duration of 2.6 days (range from $3 \mathrm{hr}$ to 7 days).

Moreover in this study, headache was mostly ipsilateral (93.7\%), mild (100\%) and required no treatment (56.3\%). Tehindrazanarivelo et al. [6] reported that headache was mostly bilateral (74\%), mild or moderate (78\%) and required no treatment (77\%). Sternic et al. [7] reported it was bilateral in 67.4\%. Marinis et al. [12] observed that the pain was on the same side of the operation in all cases (100\%), that it was severe in seven (43.7\%) patients, moderate in five (31.2\%) and mild in four (25\%) patients.

Moreover, Marinis et al. [12] observed cluster-like headache in $100 \%$ of cases, while for Sternic et al. [7], it presented continuous, dull pain in $52 \%$ of patients. In the

Table 2. Headache and mean degree of stenosis in the ipsilateral and contralateral carotid operated.

\begin{tabular}{ccc}
\hline Headache & $\begin{array}{c}\text { Mean contralateral } \\
\text { carotid stenosis (\%) }\end{array}$ & $\begin{array}{c}\text { Mean carotid stenosis } \\
\text { before surgery (\%) }\end{array}$ \\
\hline Yes & 45.8 & 86.5 \\
No & 39.6 & 84.5 \\
p & 0.36 & 0.43 \\
\hline
\end{tabular}

Table 3. Literature analyzes of headache after CAE.

\begin{tabular}{|c|c|c|c|c|c|c|c|}
\hline Series & $\mathrm{n}$ & Mean age & Male (\%) & Female (\%) & Incidence & Ipsilateral pain & Bilateral pain \\
\hline Marinis 1991 [12] & 54 & 55.8 & $40(74 \%)$ & $14(26 \%)$ & $16(30 \%)$ & $16(100 \%)$ & $0(0 \%)$ \\
\hline Sternic 1995 [7] & 187 & 63 & 147 (78\%) & $50(22 \%)$ & $46(24 \%)$ & $15(33 \%)$ & $31(67 \%)$ \\
\hline This series 2004 & 32 & 67.3 & 22 (69\%) & $10(31 \%)$ & 12 (37.5\%) & 11 (91\%) & $1(9 \%)$ \\
\hline Total & 323 & 63.3 & 245 (75\%) & $78(25 \%)$ & 105 (32\%) & $50(48 \%)$ & 55 (52\%) \\
\hline
\end{tabular}

$\mathrm{n}=$ Number of patients. 
present series, the main type of headache was pressure (81.2\%) and no patient developed cluster-like headache or presented the characteristics of a cerebral hyperperfusion syndrome, similar to other authors [6,7,13-15], but quite different from that descried in The International Classification of Headache Disorders $2^{\text {nd }}$ Edition [5].

The degree of stenosis in carotid ipsilateral and contralateral showed no relation with the occurrence of headache post CEA, confirming the findings of others authors [6].

Very few series analyzing headache following CEA have been reported [6,7,12], and analysis of these series revealed important variability in the incidence and characteristics of headache. Case reports have been published of the severe forms of headache following this procedure $[4,11$, 16-20], which may promote overestimation of the frequency of these severe forms (cluster-like and hyperperfusion syndrome).

\section{Conclusions}

Headache following carotid endarterectomy is a common condition, in most cases ipsilateral to the procedure, pressure type, mild and self-limiting.

Larger series are required to improve current definitions of the incidence, characteristics and subtype incidences of headache following carotid endarterectomy.

\section{REFERENCES}

[1] H. H. Eastcott, G. W. Pickering and C. G. Rob, "Reconstruction of Internal Carotid Artery in a Patient with Intermittent Attacks of Hemiplegia,” Lancet, Vol. 267, No. 6846, 1954, pp. 994-996.

doi:10.1016/S0140-6736(54)90544-9

[2] G. G. Ferguson, M. Eliasziw, H. W. Barr, G. P. Clagett and R. W. Barnes, "The North American Symptomatic Carotid Endarterectomy Trial: Surgical Results in 1415 Patients," Stroke, Vol. 30, 1999, pp. 1751-1758. doi:10.1161/01.STR.30.9.1751

[3] P. M. Rothwell, S. A. Gutnikov and C. P. Warlow, "Reanalysis of the Final Results of the European Carotid Surgery Trial,” Stroke, Vol. 34, 2003, pp.514-523. doi:10.1161/01.STR.0000054671.71777.C7

[4] J. Pearce, "Headache after Carotid Endarterectomy," British Medical Journal, Vol. 2, No. 6027, 1976, pp. 8586. doi:10.1136/bmj.2.6027.85

[5] J. Olesen and T. J. Steiner, "International Classification of Headache Disorders, 2nd Edition,” Journal of Neurology, Neurosurgery \& Psychiatry, Vol. 75, No. 6, 2004, pp. 808-811.

[6] A. D. Tehindrazanarivelo, G. Lutz, C. PetitJean and M. G. Bousser, "Headache Following Carotid Endarterectomy: A Prospective Study,” Cephalalgia, Vol. 12, No. 6, 1992, pp. 380-382. doi:10.1111/j.1468-2982.1992.00380.x

[7] N. Sternic, D. J. Radak, M. Svetel, V. V. Kostic and B.
Petrovic, "Headache after Carotid Endarterectomy,” Srpski Arhiv za Celokupno Lekarstvo, Vol. 123, No. 5-6, 1995, pp. 143-145.

[8] A. A. Sousa, "Carotid Endarterectomy under Regional Anesthesia,” Neurologia Medico-Chirurgica, Vol. 38, 1998, pp. 279-283. doi:10.2176/nmc.38.suppl_279

[9] A. A. Sousa, M. A. Dellaretti Filho, W. Faglione Jr. and G. T. Carvalho, "Superficial vs Combined Cervical Plexus Block for Carotid Endarterectomy: A Prospective, Randomized Study,” Surgical Neurology, Vol. 63, Suppl. 1, 2005, pp. 22-25.

[10] H. Zachrisson, C. Blomstrand, J. Holm, E. Mattsson and R. Volkmann, “Changes in Middle Cerebral Artery Blood Flow after Carotid Endarterectomy as Monitored by Transcranial Doppler," Journal of Vascular Surgery, Vol. 36, No. 2, 2002, pp. 285-290. doi:10.1067/mva.2002.125843

[11] A. Leviton, L. Caplan and E. Salzman, "Severe Headache after Carotid Endarterectomy,” Headache, Vol. 15, No. 3, 1975, pp. 207-209. doi:10.1111/j.1526-4610.1975.hed1503207.x

[12] M. De Marinis, A. Zaccaria, V. Faraglia, P. Fiorani and G. Maira, "Post Endarterectomy Headache and the Role of the Oculo-Sympathetic System," Journal of Neurology, Neurosurgery \& Psychiatry, Vol. 54, 1991, pp. 314-317. doi:10.1136/jnnp.54.4.314

[13] B. Messert and J. A. Black, "Cluster Headache, Hemicrania, and Other Head Pains: Morbidity of Carotid Endarterectomy,” Stroke, Vol. 9, 1978, pp. 559-562. doi:10.1161/01.STR.9.6.559

[14] J. R. Graham, “Cluster Headache,” Headache, Vol. 11, No. 4, 1972, pp. 175-185. doi:10.1111/j.1526-4610.1972.hed1104175.x

[15] Headache Classification Committee of the International Headache Society, "Classification and Diagnostic Criteria for Headache Disorders, Cranial Neuralgias and Facial Pain,” Cephalalgia, Vol. 8, Suppl. 7, 1989, pp. 35-38.

[16] A. Björne, B. Hindfelt and U. Havelius, "Recurrence of Cluster Headache after Carotid Thrombendarterectomy," Headache, Vol. 34, No. 4, 1994, pp. 230-233. doi:10.1111/j.1526-4610.1994.hed3404230.x

[17] O. Ille, F. Woimant, A. Pruna, O. Corabianu and J. M. Idatte, "Hypertensive Encephalopathy after Bilateral Carotid Endarterectomy,” Stroke, Vol. 26, 1995, pp. 488491. doi:10.1161/01.STR.26.3.488

[18] J. C. Breen, L. R. Caplan, L. D. DeWitt, M. Belkin and W. C. Mackey, "Brain Edema after Carotid Surgery," Neurology, Vol. 46, No. 1, 1996, pp. 175-181.

[19] S. Bouri, A. Thapar, J. Shalhoub, G. Jayasooriya and A. Fernando, "Hypertension and the Post-Carotid Endarterectomy Cerebral Hyperperfusion Syndrome,” European Journal of Vascular and Endovascular Surgery, Vol. 41, No. 2, 2011, pp. 229-237. doi:10.1016/j.ejvs.2010.10.016

[20] E. Durán-Ferreras, J. M. Aguilera-Navarro and R. Fernández-Bolaños Porras, "Post-Carotid Endarterectomy Cerebral Hyperperfusion Syndrome," Revista de Neurologia, Vol. 47, No. 3, 2008, pp. 165-166. 